\title{
AGRICULTURA FAMILIAR, ECONOMIA POPULAR E SOLIDÁRIA E COMERCIALIZAÇÃO: "BOAS EXPECTATIVAS" COMO RESULTADO DE ESTUDO NA COMUNIDADE QUILOMBOLA DE LAGOA GRANDE, FEIRA DE SANTANA-BA.
}

\author{
Geisiane dos Santos Silva ${ }^{1}$; \\ Angélica Correia Lopes ${ }^{2}$; \\ Betânia Silva Bastos ${ }^{3}$; \\ Alessandra Oliveira Teles ${ }^{4}$; \\ José Raimundo Oliveira Lima ${ }^{5}$
}

\begin{abstract}
RESUMO
O trabalho ora relatado, nasce de uma necessidade de criação de um diagnóstico sazonal e identificação das potencialidades da comunidade do grupo: Sabores do Quilombo, que até então não são tão valorizadas. Utilizando-se dos princípios da pesquisa-ação e instrumentos entrevistas semiestruturadas, o trabalho propôs-se a identificar agricultores familiares da comunidade Quilombola de Lagoa Grande através no mapeamento dos produtores rurais da comunidade fornecedora de insumos para a produção de alimentos dentro da cantina solidária III, bem como seu produtos através da visitação ás unidades familiares produtoras para entrevistas, buscando assim, possibilitar a viabilidade de uma forma de integração entre a comunidade universitária e a comunidade local. Como resultados, a pesquisa identificou quintais produtivos, compostos por produtos como, criação de pequenos animais, mandioca e seus derivados, hortaliças, e principalmente frutíferas, que aparecem no quintal de quase todos entrevistados (as), mesmo aqueles que dizem não produzirem "nada". Assim, inferiu-se, graças às reflexões realizadas na Incubadora de Iniciativas de Economia Popular e Solidária da UEFS, que a relação entre a agricultura familiar e a economia popular e solidária tem possibilitado a comercialização que vinha sendo um gargalo dessa economia e, entretanto, tem se apresentado como uma boa alternativa para a geração de trabalho e renda na comunidade quilombola de Lagoa Grande.
\end{abstract}

PALAVRAS-CHAVE: Comercialização. Agricultura Familiar. Economia Popular e Solidária.

\footnotetext{
${ }^{1}$ Graduanda do curso de Bacharelado em Engenharia de Alimentos da Universidade Estadual de Feira de Santana (UEFS). Bolsista de Iniciação Científica do CNPq. Integrante da Incubadora de Iniciativas de Iniciativas da Economia Popular e Solidária da UEFS (IEPS/UEFS).

E-mail: geeise_santos@hotmail.com

${ }^{2}$ Graduanda do curso de Bacharelado em Agronomia da Universidade Estadual de Feira de Santana (UEFS). Bolsista de Iniciação Científica PROBIC/UEFS. Integrante da Incubadora de Iniciativas da Economia Popular e Solidária da UEFS(IEPS/UEFS). E-mail: angelica.correia13@ hotmail.com

${ }^{3}$ Graduanda do curso de Bacharelado em Agronomia da Universidade Estadual de Feira de Santana (UEFS). Bolsista de Extensão PIBEX/UEFS. Integrante da Incubadora de Iniciativas de Iniciativas da Economia Popular e Solidária da UEFS (IEPS/UEFS). E-mail: betaniasbastos@gmail.com

${ }^{4}$ Doutora em Geografia pela Universidade Federal de Sergipe. Professora Auxiliar do Departamento de Ciências Humanas e Filosofia da Universidade Estadual de Feira de Santana (UEFS). Integrante da Incubadora de Iniciativas da Economia Popular e Solidária da UEFS. (IEPS/UEFS).

E-mail: alessandra.geografia@hotmail.com

${ }^{5}$ Doutor em Educação e Contemporaneidade e Coordenador do Programa de Incubadora de Iniciativas da Economia Popular e Solidária. E-mail: zeraimundo@uefs.br
} 


\section{CONSIDERAÇÕES INICIAIS}

A economia popular e solidária propõe alternativas de geração de trabalho e renda, sendo uma resposta a favor da inclusão social. Neste âmbito de inclusão, é organizada como uma diversidade de práticas econômicas e sociais sob a forma de cooperativas, associações e grupos solidários informais, que realizam atividades que tem como objetivo trabalho e renda para esses grupos comunitários (SINGER, 2008). Visto que o mercado competitivo é seletivo e muito excludente para quem não tem experiência empresarial e dispõe de reservas de capital para autos investimentos, em especial, excluem do processo socioeconômico os novos produtores que ainda desconhecidos não possuem clientela e enfrentam dificuldades para se inserirem no mercado formal.

Neste contexto, surge o processo de incubação de grupos que é desenvolvido por incubadoras. Sendo assim, as incubadoras universitárias, surgem a partir de uma conduta/ação diferente do que ocorre com a economia tradicional (competitividade e individualismo) dentro das universidades. O trabalho de incubação, desenvolvido nas incubadoras, parte de um processo de orientação educativo-político-pedagógico com grupos informais, que visa estreitar a relação da comunidade externa com a universidade (PITA, LIMA e LIMA 2015).

Desta maneira, a Incubadora de Iniciativas da Economia Popular e Solidária da Universidade Estadual de Feira de Santana (IEPS/UEFS), constitui-se de um programa interdisciplinar com início de suas atividades em 2008, que conta com uma equipe multidisciplinar de docentes, discentes, colaboradoras (es) e voluntárias(os), juntos desenvolvem atividades, de pesquisa e extensão, onde acompanham quatro iniciativas atualmente em processo educativo de produção associada.

Desde, então a IEPS/UEFS desenvolve, por meio de projetos de extensão e/ou pesquisa outras atividades de caráter continuado junto à comunidade universitária e externa, não só um espaço para diálogo com as iniciativas de economia popular e solidária, estimulando-se a geração de trabalho e renda, como também um espaço educativo de disseminação de informações e fortalecimento da economia popular e solidária, priorizando-se a comunidade local e o Território Portal do Sertão (PITA,LIMA, LIMA, 2015,p.70)

A pesquisa acontece de tal forma que, insere-se no âmbito da Economia Popular e Solidária, ora apresentada como proposta de estabelecer relações de trabalho mais justas, solidárias e atentas ao bem viver dos sujeitos, assumindo assim um papel importante na transformação desses, que buscam nessa "outra economia", uma forma de geração de trabalho e renda, exercida de forma coletiva e que não visa apenas à lucratividade, mas um conjunto de 
aspectos que estabelecem uma relação estreita entre trabalho e qualidade de vida, ambos como peças importantes neste processo, viabilizando as relações entre o modo de consumir, pensar e agir do ser humano.

Com efeito, por se tratar de uma economia que se contrapõe ao modelo capitalista, a Economia Popular e Solidária busca a valorização do trabalhador e suas relações coletivas de trabalho, segundo Lima (2016,p.4) “[...] ainda é uma economia considerada periférica, pois é aquela que, tendo em vista a sua dinâmica, emerge de reações adversas ás imposições do capitalismo globalizante centralizado e verticalizado no poder do mercado".

Desta forma, a sua prática tem surgido em meio a situações adversas condicionadas à alienação ao capitalismo, tornando-se uma busca pela manutenção do trabalho e por melhores condições, permitindo ao trabalhador emancipação a partir de uma democratização econômica.

\footnotetext{
Essa economia, entretanto, apresenta características ou traços referentes aos laços de pertencimento culturais e geográficos, saberes locais, políticos, educacionais, pertinentes às políticas públicas específicas, entre outros atributos. Favorece o movimento contra-hegemônico pelo desenvolvimento local solidário em detrimento do desenvolvimento tradicional, por conta da possibilidade da construção de uma articulação no seu cotidiano, nas suas relações genuínas e orgânicas. (LIMA, 2016, p.4)
}

Nesta esteira, entende-se a Economia Popular e Solidária como experiências que permitem a construção de um espaço pensando para além de uma visão econômica na busca de geração de trabalho e renda, tendo como alicerce a inclusão social dos sujeitos, levando em conta a sustentabilidade, o uso dos recursos naturais e conscientização ambiental.

Dentre os diversos formatos de iniciativas da economia popular e solidária, que se apresentam tanto no âmbito do campo como da cidade, onde compreende trabalhadores organizados coletivamente, têm-se: associações, grupos produtivos, cooperativas de agricultura familiar, redes de produção, comercialização e consumo, clubes de troca, bancos comunitários, cooperativas de crédito, fábricas recuperadas pelos trabalhadores. E em se tratando de tais grupos, as incubadoras universitárias tem desenvolvido um papel importante de fornecer suporte para o seu desenvolvimento, fortalecimento e produção do conhecimento.

Entre as diversas formas de iniciativas, apresenta-se aqui o caso do grupo Sabores do Quilombo, sendo possível a primeira experiência com um grupo produtivo rural, no espaço da Universidade e aliados a proposta do Projeto Cantinas Solidárias, que constitui-se de um espaço político-educativo-didático-pedagógico, diferenciado de comercialização, onde é 
possível desfrutar de uma alimentação, especialmente lanches, oriundos de produtos e serviços da Economia Popular e Solidária e Agricultura Familiar, buscando o desenvolvimento da cultura regional e favorecimento do desenvolvimento local.

Assim, o Projeto Cantina Solidária III, tem como objetivo:

\begin{abstract}
Promover o processo de incubação de um grupo popular solidário enquanto iniciativa da economia popular e solidária no espaço da Cantina do Módulo I, como lócus pedagógico para a realização das atividades de organização, comercialização, formação e capacitação dos envolvidos no processo, tanto no sentido de proporcionar oportunidade de geração de trabalho e renda, quanto, e de forma especial, oportunidade de aprendizado sócio-político para a autonomia e luta enquanto classe, compreensão dos processos de produção de desigualdade de renda e riqueza e reconhecimento do valor e potencialidades dos produtos, saberes, cultura, realizações e história locais. (IEPS/UEFS, 2016, p.9)
\end{abstract}

O processo seletivo para o referido projeto, o qual o grupo selecionado ocuparia a Cantina Solidária, no campus da Universidade Estadual de Feira de Santana, sempre foi realizado de forma tradicional, através de edital escrito e publicado no Diário Oficial e outros meios de comunicação. Porém com passar do tempo foi-se percebendo que muitas vezes não atingia os grupos que de fato possuem as características de uma incubação em economia popular e solidária, o que não se constitui em uma problemática, visto que todo trabalho realizado constitui-se em aprendizado, porém o objetivo principal não estava sendo atingido.

Desta forma de acordo com experiências anteriores, adotou-se um procedimento diferenciado, através da seleção prévia de grupos com as características consideradas dentro das perspectivas de organização coletiva e desenvolvimento local. A seleção foi realizada através de um cadastro interno existente na IEPS/UEFS, composto de grupos que mantém contato com a Incubadora e/ou participou de atividades realizadas na própria instituição.

A partir dessa seleção, puderam-se realizar visitas aos grupos em suas respectivas comunidades ou local de produção. Com isso, um dos grupos contemplados foi o de 12 mulheres da Comunidade Quilombola Lagoa Grande localizada no distrito de Maria Quitéria, zona rural da cidade de Feira de Santana, que além de características desejáveis identificadas demonstraram interesse em participar da seleção. O processo de pré-incubação do grupo foi iniciado em abril de 2016, com a realização de ações formativas, organização prévia do trabalho, escolha dos componentes do grupo pela comunidade e escolha do nome que foi decidido a partir das atividades coletivas e escolha dos integrantes do grupo: Sabores do Quilombo. 
No que tange à comercialização, base econômica para a geração de renda para o grupo, segundo Padilha Júnior (2006) “[...] entende-se por comercialização o desempenho de todas as funções ou atividades envolvidas na transferência de bens ou serviços do produtor ao consumidor final." O processo de comercialização ocorre desde os tempos mais antigos, com a prática do escambo, que era baseado em trocas naturais onde as partes decidiam livremente a quantidade de produtos que poderiam envolver as suas negociações. Com o aumento da população e áreas urbanas o processo de comercialização foi se aprimorando ao longo dos anos para poder atender a demanda dos consumidores.

Ao se tratar de comercialização de produtos regionais e desenvolvimento local o fortalecimento através de redes na própria comunidade, e cantina/comunidade se faz importante, pois a comercialização de alimentos da comunidade evidencia o desenvolvimento local, na medida em que os agricultores, principais responsáveis pelo crescimento dessa prática, e então, são visivelmente envolvidos no processo de produção de alimentos. Onde as matérias primas para elaboração dos alimentos são oriundas do local em que vivem, colocando em prática a valorização e fortalecimento da identidade do seu lugar.

O aproveitamento desses produtos além de favorecer a comercialização local, possibilita a apresentação de novos produtos fonte de propriedades nutricionais variadas, muitas vezes pouco conhecidas. Nesse contexto, a utilização de alimentos oriundos da agricultura familiar orgânica ou de base agroecológica, possibilita uma forma de consumo sustentável e assume um papel importante em vários âmbitos da sociedade que garante não apenas relações econômicas - compra e venda de produtos locais - , mas, outros fatores como as crenças e costumes. Desse modo, esses fatores vão influenciar na forma de cultivo e consumo, além de proporcionar qualidade de vida por meio de uma produção livre de agrotóxicos, visto que a sociedade se mostra cada vez mais preocupada com origem e processamento dos produtos comercializados.

Em relação aos aspectos ambientais, age-se com base nos princípios agroecológicos através do manejo e uso sustentável do solo. E segundo Lima (2012) outro destaque refere-se à construção de um processo político educativo que leva à comunidade a defesa orgânica da forma de um desenvolvimento endógeno. Nesta trilha, a atividade agrícola familiar, por sua vez, constitui-se de um sistema simples de produção, usualmente adotado por pequenas propriedades rurais, onde o sustento e a sobrevivência da família depende do manejo da terra. Observa-se ainda que a prática da agricultura familiar em sua constituição apresenta pilares como respeito aos aspectos culturais, sociais e principalmente ambientais. 
Uma das características que permeiam a agricultura familiar é a presença de um espaço que faz parte da composição natural da paisagem, o qual é chamado de quintais produtivos, espaços estes ricos e diversificados que cumprem o papel de fortalecer a produção, ajudando na soberania e segurança alimentar das famílias. O que denominamos Quintais Produtivos ${ }^{6}$ é o espaço ao redor da casa que comporta atividades diversas como, por exemplo: criação de pequenos animais (cachorros, aves, caprinos, ovinos, suínos), além de atividade agrícola com cultivos de plantas medicinais, frutíferas, hortaliças, tubérculos, ancorados por trocas de saberes constantes e mantidos pela responsabilidade nas mais diversas gerações.

O Quintal Produtivo oferece várias vantagens para toda a família. Essas vantagens possibilitam maior comodidade, menor espaço de tempo para executar as atividades de cultivo, manejo e colheita dos produtos de época. Com o quintal produtivo é possível da janela ou porta de casa observar qual planta ou fruto está no ponto de colheita bem como verificar a ocorrência de algum desequilíbrio, desta forma poder colher o fruto adequado e maduro no período correto sem deixar que passe do ponto ou se perca, por isso e tomar medidas preventivas contra o ataque de insetos e doenças. Outro fator vantajoso é ter o alimento próximo da casa sem a necessidade de se deslocar grande distância para obtê-lo para o preparo das refeições sendo assim em um dia de calor intenso é só olhar para o quintal e ir coletar a melhor fruta para preparar um delicioso suco para se refrescar. (PEDROSA, 2016, p.2)

Observa-se que nos quintais encontra-se uma diversidade da produção familiar, sendo este espaço responsável por fornecer a maioria dos alimentos que compõe a mesa da família, bem como garantia de seu sustento ou complementação de renda. Além disso, compõe-se em um espaço de laser responsável pela formação da paisagem local, tendo na maioria das vezes a mulher como a responsável pelos trabalhos e participantes das atividades que permeiam.

O trabalho realizado nasce da necessidade de criação de um diagnóstico sazonal e identificação das potencialidades da comunidade que até então não são tão valorizadas. Além disso, entende-se que estes produtos vêm tendo um espaço de comercialização conjunto com a Cantina Solidária.

6 Os quintais produtivos da pesquisa, em sua maioria, demonstraram espaços, em áreas, via de regra, com aproximadamente uma tarefa até 3 tarefas. Uma tarefa que vale a 4356 m2 na Bahia. 


\section{ASPECTOS METODOLÓGICOS}

Compreender uma pesquisa-ação pressupõe compreender o todo do qual esta faz parte, com todos os seus meandros, lugares e sujeitos envolvidos. Assim, a Comunidade de Lagoa Grande, está situada entre as coordenadas geográficas $12^{\circ} 06^{\prime} 58^{\prime \prime}$ e $12^{\circ} 08^{\prime} 37^{\prime \prime}$ de latitude sul e 38 59'6" e 38 59'58' de longitude oeste, distante da sede do distrito de Maria Quitéria em cerca de 1,5 km e do centro da sede municipal de Feira de Santana em 17 km.

Assim nomeada por conta da lagoa presente a aproximadamente $6 \mathrm{Km}$ da área, abrigou, no passado, escravos fugidos de várias regiões do estado que foram trabalhar nas terras de São José, e que por lá fixaram moradia e formaram famílias. Compõe a primeira comunidade remanescente de Quilombolo reconhecida no município de Feira Santana, sendo reconhecida como território quilombola pelo Município e pela Fundação Palmares, em 2007.

Atualmente, encontra-se em processo de reconhecimento pelo Instituto Nacional de Colonização e Reforma Agrária (INCRA) e também pelo município para mudança de endereço residenciais de água e luz de Fazenda Lagoa Grande para Fazenda Quilombola Lagoa Grande. A comunidade conta com cerca de 200 famílias, de acordo com o mapa, registrado pela prefeitura, no entanto, existe uma diferença territorial descrita entre os moradores e a prefeitura, enquanto reconhecimento e pertencimento da comunidade.

$\mathrm{O}$ acesso à comunidade é feito principalmente, pelo uso do transporte alternativo de vans que faz a linha Ovo da Ema/São José; São José/Carro Quebrado; transporte de ônibus da linha São José/Carro Quebrado pela empresa Rosa e Trans. Rural, ocorrendo em horários prédefinidos, que passa na estrada principal de acesso à comunidade, no entanto, existem outras linhas, que se destina apenas até o distrito, sendo necessário recorrer ao serviço de moto-táxi que atua de forma complementar entre a sede do distrito até a comunidade de Lagoa Grande.

A experiência ora relatada tem início em fevereiro de 2017 com reunião de planejamento e elaboração das entrevistas semiestruturada aplicadas aos agricultores (as) da comunidade, finalizada parcialmente em junho de 2017. Inicialmente buscou-se aprofundar mais um pouco na história da comunidade, visando obter um maior embasamento teórico sobre algumas temáticas.

A pesquisa em sistematização propriamente, inicia-se em fevereiro de 2017 com presença na reunião do Grupo Sabores do Quilombo, reunidos na própria comunidade, na casa de uma moradora bastante conhecida, de nome popular Maria Parteira ${ }^{7}$, local este, onde

\footnotetext{
${ }_{7}$ Maria Parteira, como é popularmente conhecida, exerceu durante muito tempo o ofício de parteira na comunidade e também no distrito. Hoje em função das burocracias, não exerce o ofício, mas ainda
} 
acontecem a maioria das reuniões/oficinas de formação com o grupo. Sendo então, apresentada a proposta do trabalho ao grupo e pedido de apoio, para realizar o reconhecimento da Comunidade e divulgação aos moradores, para melhor aceitação do trabalho, uma vez que éramos conhecidos apenas por poucos moradores e poderíamos nos deparar com alto índice de rejeição pelos moradores, tendo em vista as características de confiabilidade que permeiam o meio rural.

O reconhecimento da comunidade ocorre no dia 07 de março de 2017, uma terça-feira, onde contou-se com ajuda de umas integrantes do grupo, (e que também é conhecida na comunidade por vender seus produtos dentro dos eventos que ocorre na sua comunidade e/ ou em São José ou mesmo a venda de seus produtos na sua porta). Sendo este um passo de extrema importância para o início do trabalho, onde seria possível, traçar um mapa de localização da comunidade, identificando seus limites.

A execução das entrevistas inicia-se logo, após o reconhecimento, ainda no dia 07, onde foram aplicadas algumas entrevistas e logo após, foi analisada a sua aplicabilidade, sendo necessária uma adequação das perguntas para um melhor entendimento, bem como alteração na ordem das perguntas.

Nesta esteira, para aplicação das entrevistas foi adotado a localização territorial que é reconhecida pela própria comunidade como sendo comunidade de Lagoa Grande. Foram realizadas duas entrevistas fora dos limites territoriais adotados pela comunidade, onde uma trata-se de uma moradora e também integrante do Grupo Sabores do Quilombo que se encontra entre a divisa de Lagoa Grande e Lagoa da Camisa (comunidade vizinha), sendo esta entrevista realizada, devido a família já manter um vínculo de fornecimento para a Cantina Sabores do Quilombo, tendo em vista que foram feitas entrevistas com a maioria das integrantes do grupo e o outro caso, trata-se de um morador bastante conhecido e referenciado pela comunidade que de acordo com os limites da prefeitura ele integra a comunidade, no entanto, enquanto reconhecimento ele não se acha pertencente a comunidade de Lagoa Grande e sim, à Comunidade de Carro Quebrado, mas, nos foi recomendado por uma moradora como efetivo quilombola.

As entrevistas semiestruturadas foram compostas por 25 perguntas, sendo aplicadas dentro de unidade familiar ${ }^{8}$, e dentro de famílias compõe a mesma unidade familiar,

presta serviço rápido de atendimento, em caso, de necessidade, até o deslocamento da parinte ao hospital, ou maternidade.

${ }^{8}$ Entende-se aqui como unidade familiar um grupo de famílias que moram próximas, onde a maioria das vezes as matriarcas da família são responsáveis pela produção e o restante do familiar ajuda no desenvolvimento da produção 
pois existiam produções diferenciadas entre as famílias chegando uma parte a produzir e a outra não produzir ou mesmo apresentarem produções distintas para cada família dentro da unidade familiar.

\section{RESULTADOS E DISCUSSÕES}

Ao longo do desenvolvimento do trabalho era notável, a familiarização dos moradores e também dos motoristas e cobradores (a) da van (transporte mais comum para a localidade), bem como a expectativa dos moradores (as) que ainda não haviam sido visitados para serem entrevistados (as), além do reconhecimento pelo trabalho que estava sendo desenvolvido e o modo de recepção nas suas casas.

A pesquisa foi realizada com 106 quilombolas compreendendo um total de 73 mulheres e 33 homens, entre a faixa etária de 13 a 76 anos. Observou-se que a comunidade é marcada por uma riqueza de variedades de produção agropecuária desde criação de pequenos animais, ao cultivo da mandioca e seus derivados, ou cultivo do milho (Zea mays) e feijão (Phaseolus vulgaris); hortaliças, além da diversidade de frutas, que apareceram em todas as casas, “ todo mundo tem um pé de alguma coisa no seu quintal”, mesmo aquele que diz não produzir "nada".

A produção pecuária é voltada para a criação de pequenos animais: galinhas (Gallus gallus domesticus), suínos (Sus scrofa domesticus), ovinos (Ovis aries), caprinos (Capra aegragrus hircus), destinando-se, principalmente, para o consumo próprio e venda na própria comunidade. Apenas um dos entrevistados apresenta criação de bovinos (Bos taurus taurus/Bos taurus indicus), trata-se de uma propriedade com maior extensão de terras e com atividades mais diversificadas, e que são criados, principalmente na época chuvosa.

Dentre os plantios tradicionais de sequeiros destacam-se: mandioca/aipim (Manihot esculenta), milho (Zea mays), feijão carioca (Phaseolus vulgaris), feijão de corda ou macaça (Vigna unguiculata), andu (Cajanus cajan), batata-doce (Ipomoea batatas), abóbora(Cucurbita L.), jiló (Solanum aethiopicum), maxixe (Cucumis anguria), hortaliças, como: coentro (Coriandrum sativum), cebolinha (Allium schoenoprasum), couve (Brassica oleracea) e amendoim ${ }^{9}$ (Arachis hypogacea) que são apenas cultivados na época chuvosa ${ }^{10}, \mathrm{o}$ qual é possível identificar o espírito solidário presente na comunidade, que mesmo com o

\footnotetext{
9 O plantio de amendoim, não é uma cultura de tradição desenvolvida pela comunidade. A comunidade que já apresentou um histórico de monocultura do plantio do amendoim, atualmente, mantido apenas por alguns, por tradição.

10 A época chuvosa inicia-se no outono. Sendo os plantios efetuados entre março e abril.
} 
passar dos anos, ainda se mantêm, por meio da prática da troca de mão em mão da semente ${ }^{11}$, que acontece desde o preparo da terra, através de capinas, ao plantio da sementes e a colheita das espécies. Embora a prática da "troca de mão em mão", tenha diminuído com o passar dos anos, ela constitui-se de uma importante dinâmica para os pequenos agricultores, para manejar a terra, além de permear a troca de suas experiências e partilharem seus conhecimentos adquiridos.

Em relação ao plantio de culturas permanentes destacam-se as frutíferas, que aparecem em quase todos os quintais, mesmo daqueles que não plantam nada em seu quintal, tem um pé de alguma frutífera na sua propriedade. As frutas que mais aparecerem são caju (Anacardium occidentale), coco (Cocos nucifera L.), laranja (Citrus sinensis), manga (Mangifera indica), acerola (Malpighia emarginata), banana (Musa ssp.), seriguela (Spondias purperea), licuri (Syagrus coranata) limão (Citrus limonium), pinha (Annona squamosa), cajá (Spondias mombim), jaca (Artocarpus heterophyllus), goiaba(Psidum guajava), graviola (Annona muricata), tamarindo(Tamarindus indica).

Em complementaridade, as frutas como mamão (Carica papaya), umbu (Spondias tuberosa), tangerina,(Citrus reticulata) pitanga (Eugenia uniflora), noni (Morinda citrifolia), fruta pão (Artocarpus altilis), jamelão (Syzygium cumini), carambola (Averrhoa carambola), abiu (Pouteria caimito), jambo (Syzyguim jambos), amora (Morus nigra), romã(Punica granatum), jabuticaba(Plinia cauliflora) e melancia (Citrullus lanatus), estão presentes em poucos quintais.

Com efeito, embora, a maioria dos quintais apresentarem em comum a maioria das espécies agrícolas, cada morador desenvolve, de forma diferenciada o manejo do seu quintal, ficando evidente a diferença de cada quintal com um arranjo único, onde cada um possui suas peculiaridades e atrativos.

$\mathrm{Na}$ maioria das vezes, a produção não é absorvida pela unidade familiar e acabam sendo desperdiçados, de modo que, a destinação para a comercialização nas Cantinas Solidárias da UEFS, está sendo uma opção para esta parte de produtos que não é absorvida, estabelecendo desta forma outro aproveitamento para estes produtos ao passo em que resolve o problema do desperdício, além da possibilidade de geração de renda extra para aquele agricultor/agricultora, uma vez, que estes em muitos casos, não comercializam o seu excedente, preferindo perder ou doar a parentes/amigos, pois, argumentam não compensar os custos da ida à feira para comercializar.

\footnotetext{
${ }^{11}$ Prática realizada pela agricultura familiar, onde um vizinho auxilia ao outro a realizar uma atividade, sem que haja remuneração para isso.
} 
Além da identificação dos produtos, as pesquisadoras de Iniciação Científica puderam ter uma troca de experiência ímpar com os mais velhos da Comunidade, além de poder conhecer um pouco mais da riqueza e sabores existentes na comunidade Quilombola de Lagoa Grande

É possível ainda identificar que alguns agricultores demostram não dá importância e/ ou desconhecerem o potencial das espécies que produzem, ou ainda manter o foco em apenas uma forma de exploração da espécie. Em umas das entrevistas uma moradora relata que embora tenha alguns pés de bananeira no quintal, ela acaba não dando importância às bananas e que mantém o cultivo para poder utilizar a palha na produção do bolo de palha ${ }^{12}$.

Destaca-se a articulação que é realizada por uma moradora da comunidade onde realiza o trabalho de coleta de frutas dentro da comunidade de casa em casa, sendo essas frutas levada para venda na feira livre, juntamente com outros produtos agrícolas que ela cultiva, devolvendo metade das sobras das vendas dos frutos ao morador que forneceu a fruta. Essa prática é bastante reconhecida pela comunidade por ser tratar de uma alternativa que evita os desperdícios dos produtos/frutas que não são absorvidos pela família, no entanto há ainda uma resistência por alguns moradores, em ceder suas frutas. Apesar de contribuir para diminuição dos desperdícios esta prática não consegue sozinha resolver o problema dos desperdícios, tendo em vista o grande número de cada espécie frutífera existente na comunidade e ainda o fato de cada espécie ficar no ponto de colheita ao mesmo tempo. Sendo, assim, necessárias outras formas de minimizar os desperdícios ou estimular o beneficiamento ou a comercialização dos produtos locais.

Aproximadamente, 82 agricultores (as), o que corresponde cerca de $78 \%$ dos (as) entrevistados (as) se colocaram à disposição para comercializar seu excedente para a Cantina Solidária. Para muitos (as) esta poderá ser uma forma de diminuir o desperdício e garantir uma renda extra e ainda colaborar com a valorização de produtos característicos da sua região, garantindo a venda por um preço mais justo, o que muitas vezes não se consegue quando seu produto é vendido aos atravessadores da região. Para outros a possibilidade de venda para o grupo da Cantina reduziria a ida ás feiras livres aventurar uma venda e acabar vendendo a preços baixíssimos para não retornar para casa com a mercadoria.

Assim, os(as) agricultores (as) interessados (as), passaram a compor um banco de dados da IEPS, possibilitando o levantamento de possíveis agricultores como potenciais

12 Iguaria nordestina feito com a massa de puba (mandioca). Na sua composição além da massa da puba, leva cravo, canela, leite de coco e coco, sendo assada no forno a lenha, envolto em folha de bananeira. 
fornecedores de matéria-prima, construindo elementos bases para a formação de redes de comercialização, objeto de execução de planos de trabalhos subsequentes da IEPS.

\section{CONSIDERAÇÕES FINAIS}

O mercado competitivo é excludente para os novos produtores, que por serem ainda desconhecidos não possuem clientela e enfrentam dificuldades de para se inserir no mercado, o que minimiza o seu tempo sobrevivência produtiva na sociedade.

As ações de pesquisa, extensão e diálogos diversos com as comunidades, povoados, quilombos, e outras perspectivas de economia popular e solidária que se baseia nos princípios de relações solidárias, cooperação, autogestão, valorização dos produtos regionais e locais é o primeiro passo para que se possa entender sobre o modo de produção de comunidades e a existência fática de economia plural e não sendo necessária a submissão cega a hegemonia mercadológica capitalista.

Nesta esteira, a universidade via extensão e/ou pesquisa, ao desenvolver projetos que auxiliem nas atividades desses pequenos produtores que por muitas vezes não tem acesso a informações e possuem, quase sempre, deficiências formativas, promovem os princípios elucidados pela literatura, mas não tem incentivo ou não acreditam no próprio trabalho que desenvolvem nem no seu conhecimento prático, que por vezes, não há comparação com o que está descrito nos livros, manuais e revistas destinados a trabalhadores desta natureza.

Com efeito, infere-se que existe na comunidade uma diversidade de produtos e/ou insumos locais que não são efetivamente valorizados comercialmente, em detrimento de outros de forte apelo em marketing nos mercados convencionais, mas, ainda assim a comunidade continua cultivando para utilização doméstica, sendo estas diversidades de produtos e/ou insumos, em sua maioria, não absorvidas pela unidade familiar e acabam se perdendo.

Neste sentido, esta parcela da produção que não é absorvida está sendo destinada para a comercialização nas Cantinas Solidárias da UEFS trazendo, desta forma, outro aproveitamento para aquele produto e possível geração de renda extra para aquele agricultor/agricultora criando atividades em redes que valorizem o bem viver e interação entre os produtores que vivem na mesma comunidade, favorecendo o desenvolvimento local, embora esse processo por si só não garanta uma estabilidade econômica local, salvo politicas publicas direcionadas a tal situação, o que, infelizmente, não se vislumbra perspectivas dada o 
baixo envolvimento do poder publico local no melhoramento da vida das classe populares ou vinculadas à economia plural.

Dessa forma, a comercialização dos produtos da comunidade pode certamente possibilitar uma relação de troca entre a comunidade local e a comunidade acadêmica, além de outras possibilidades, provendo assim o incentivo ao desenvolvimento local, estímulo a uma cultura alimentar tradicional e valorização da comunidade por vias de relações de consumo de uma alimentação mais saudável e uma produção associada.

\section{REFERÊNCIAS}

GOERCK, Caroline; FRAGA Cristina Kologeski. Economia Popular Solidária no Brasil: um espaço de resistência as manifestações de desigualdade da questão social. Vivencias: Revista Eletrônica de Extensão da URI. v.16, n.9, p.103-111. Maio/2010

IEPS/UEFS. Projeto Cantina Solidária III. Feira de Santana, Bahia, 2016. p.1-23.

LIMA, J.R.O. Economia Popular e Solidária e desenvolvimento local: relação protagonizada pela organicidade das iniciativas. Otra Economía,10 (18):p.3-17, enero-junio 2016

LIMA, J.R.O. Economia popular e solidária e desenvolvimento local solidário: análise dos processos educativos e de economia política inerente à incubação de iniciativas econômicas populares solidárias. Comunicação apresentada no I Seminário do Fórum de Pesquisa da Linha 3-Educação, Gestão e Desenvolvimento Local Sustentável do PPGEdu/UNEBSalvador-mai. 2012.

PEDROSA, Rosangela Aparecida. A importância dos quintais produtivos na Economia Familiar. Minicurso apresentado no Agroecol-Dourados-MS, nov.2016.

PITA, F.A; LIMA, J.R.O; LIMA, C.E.S. Normatizando solidariedade: experiência de construção coletiva de regras de uma cooperativa informal de Economia Solidária. Otra Economía, 9 (16):p.69-78, enero-junio 2015.Disponível em< http://revistas.unisinos.br/index.php/otraeconomia/article/view/otra.2015.916.05>

SINGER, P.I. Globalização e Desemprego: diagnóstico e alternativas. $7^{\circ}$ ed. São Paulo: Contexto,2008. 